\title{
MODELLING THE IMPACTS OF RESOURCE SHARING ON SUPPLY CHAIN EFFICIENCY
}

\author{
Gong, D.; Liu, S. \& Lu, X. \\ School of Economics \& Management, Beijing Jiaotong University, Beijing, China \\ E-Mail: gongtuipigua@163.com,shfliu@bjtu.edu.cn, xclu@bjtu.edu.cn
}

\begin{abstract}
This study investigates the impacts of resource sharing on the supply chain efficiency. Due to the increased emphasis on efficiency, modern supply chain processes are no longer labour-intensive. Supply chain management should particularly consider resource sharing. The queuing and AnyLogic approaches are developed in this paper to model and simulate complex supply chain operations. First, based on the queuing theory, this paper conducts a mathematical analysis on the resource sharing mode's impact on supply chain efficiency; then, it performs a simulation for the resource sharing mode's impact on supply chain efficiency. Then, in a case from the express industry, this paper quantitatively analyses the resource sharing mode's impact on the average service length of orders, the average service time of orders, the loss rate of orders and the utilization of resources. Finally, through simulation, this study shows that the resource sharing mode is superior to the resources exclusive mode in all of the above aspects. For example, the service length of the resources exclusive mode is much longer than the total service length of the resource sharing mode. However, the service time of the resources exclusive mode is nearly equal to the total service time of the resource sharing mode; the resource sharing mode's loss rate is approximately $90 \%$ lower than the loss rate of the resources exclusive mode.

(Received, processed and accepted by the Chinese Representative Office.)
\end{abstract}

Key Words: Resource Sharing Mode, Queuing, Modelling, Simulation, AnyLogic

\section{INTRODUCTION}

Supply chain resources mainly include those that can be transferred across organizations, such as physical resources (manpower and equipment), information resources, explicit knowledge resources (patents and brands) and capacity resources (individual capacity), as well as those that are embedded in the organization, such as tacit knowledge resources and organizational resources. This paper focuses on physical resources.

A supply chain is an ecosystem; different enterprises comprise a particular supply chain ecological community. In addition, supply chain management should comprehensively consider customers, suppliers, manufacturers, and distributors. The competition can be formed solely by the cooperation between industry bodies; furthermore, supply chain activities cannot be achieved until the resources of different industry bodies are integrated. Not only is the supply chain cooperation significant, but it is the means of eliminating the obstacles across industry bodies. Therefore, the requirements for supply chain efficiency will be rigid. In particular, the development of high energy consumption, high emissions and high pollution leads to environment problems; furthermore, due to the increased emphasis on technology, modern manufacturing processes are no longer labour-intensive. Under these circumstances, the problem of supply chain resource sharing needs to be urgently solved.

Supply chain resource sharing aims to integrate different resources in the value chain. Findings from the existing literature indicate that the process of supply chain resource sharing mainly includes goal setting, resources recognizing, resources obtaining and resources maintaining. Therefore, the full interpretation of resource sharing (that is resources recognizing) will provide a theoretical and practical foundation for resources obtaining and resources maintaining. 
For goal setting, supply chain management should involve material flows, information flows, and finance flows in a network consisting of customers, suppliers, manufacturers, and distributors [1].Additionally, effectively coordinating and integrating these flows is essential to effective supply chain management [2]. Lepak et al. [3] discussed the deep-seated meaning of logistics resources integration in terms of the goals of value creation, the process of value creation, and the process of value capture, based on society, organization, and individual levels; Rajsman and Pros [4] thought that quality, environment, occupational health and safety management systems represent a modern way of organizing work and company administration.

For resources obtaining from the perspective of customer needs, Akanle and Zhang [5] proposed the optimization of the configuration for supply chains, and they developed a multi-agent model that coordinated an iterative bidding mechanism based on interactive algorithms; in addition, they obtained the optimum based on a genetic algorithm. Brintrup [6] established the supplier selection model of the multi-agent, the multi-target, and the multi-role with the objective to reduce the transaction time and increase corporate revenue. Against the background of a global supply chain manufacturing network, Jiao et al. [7] established a multi-agent (upstream and downstream enterprises involved in a supply chain), multi-contracting negotiation (customer demand) model, which is helpful for addressing spontaneous or semi-spontaneous problems in a supply chain; similarly, Bronja and Bronja [8] presented a new, two-phase, multi-criteria procedure to select a supplier in the car exhaust system. Bhattacharyya [9] analysed the supply chain cost problem and developed the LINGO program for simulation. Ultimately, the researcher found the optimal resource integration path.

For resources maintaining: information technology can achieve supply chain synergies; for example, Prajogo and Olhager [10] proposed the logistics resources integration concept on an information background. The integration of logistics information resources can drive the integration of logistics resources, information, and information sharing. This integration has a significant impact on supply chain performance. Wamba and Chatfield [11] discussed the application of RF technology in the logistics resources integration. Salman et al. [12] developed the fractional frequency reuse technique to get new static resource utilization approach, so as to enhance resource exploitation in Worldwide Interoperability. Game theory can realize internal incentives by maintaining a fair distribution of benefits; for example, Handfield and Nichols [13], Sahay [14] considered that the trust mechanism is of great importance to supply chain management, assuming that robust supply chains are needed to ensure mutual trust and responsibilities among the system main bodies for a long time. Mavromoustakis, Yu, Yang and Chard, et al. [15-18] also focused on the application of information technology.

There are certain theories regarding the interpretation of resource sharing, such as the economies of scale and the economies of scope (Drucker, Magretta and others), economic externality (Watts, Arthur, Madhok and others), and resources and capabilities (Dyer, Singh and others).

In sum, the existing literature mainly focuses on goal setting and the theories of resources recognizing, resources obtaining and resources maintaining, whereas the practices of resources recognizing is of particular importance. Thus, Gill [19] proposed an activity-based costing model to identify resource under-utilization to identify the potential bottlenecks in the manufacturing process; however, the related research has not focused on this.

The research questions in this study are: with a background of resources recognizing, how is the resource sharing mode superior to the resource exclusive mode and in which aspects is it superior? Currently, the aforementioned problems have not yet been resolved in related studies; furthermore, in an effort to improve productivity and optimize resource use, the 
modelling and simulating method was developed to reflect real-world complex construction operations $[20,21]$. Therefore, in this study, in an express industry case, we propose the use of the queuing model to illustrate the problems of resource sharing with the help of an AnyLogic simulation platform; that is, how the resource sharing mode can quantitatively affect the average service length of orders (the service length, below), the average service time of orders (the service time, below), the loss rate of orders (the loss rate, below) and the utilization of resources. We organize this paper as follows: in the following section, we introduce the queuing method, which provides the base for the resource sharing theoretical model. In section 3, we present the simulation models using AnyLogic and obtain the simulation results through which we verify the model. Finally, we conclude this study.

\section{THE THEORETICAL MODEL}

In the express company, the basic activities include receiving, sorting, distributing and servicing. Distribution is the most important activity, and it occupies the highest portion of the express cost. Because speed plays an important part in an express company, speed depends on the express distribution. Therefore, an express company should improve its efficient use of existing resources and maximize the utilization of logistics centres and transport equipment, thereby reducing the express cost.

A typical express order distribution process is shown in Fig. 1.

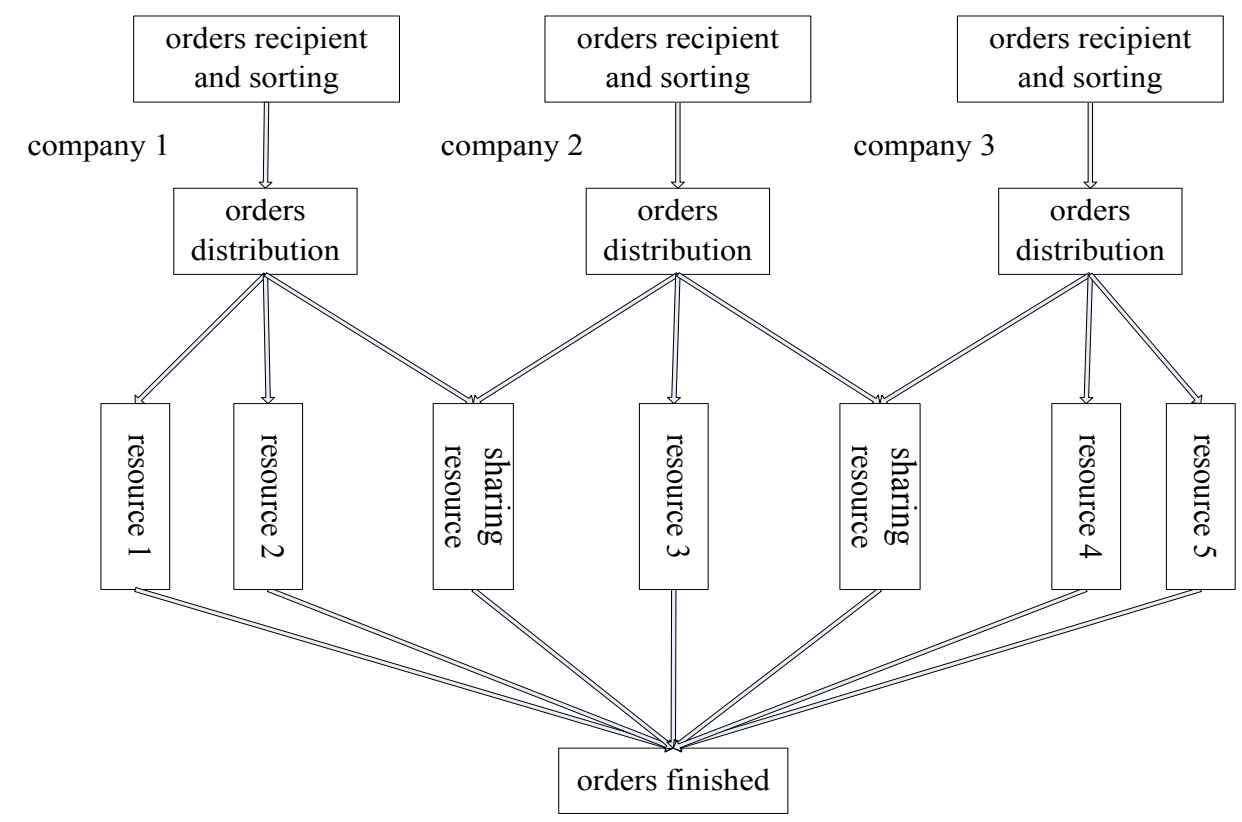

Figure 1: The orders distribution process.

In Fig. 1, the order distribution will be completed using private resources or sharing resources. Additionally, the orders distribution can be recognized as the "birth-death" process in a queuing system. "Birth" refers to the orders recipient; "death" refers to the completed orders.

$N(t)$ is the orders number in time $t, N(t)=n, n=0,1,2, \ldots$; the orders recipient time $r t=-e^{-\lambda n}$ (Exponential distribution, $\lambda_{n}$ is a parameter), the orders finished time $f t=-e^{-\mu n}$ (Exponential distribution, $\mu_{n}$ is a parameter), and the one order received or finished in time $t$. When the system is in the steady state, $N(t)$ is changed as $p_{n}, p_{n}=0,1,2, \ldots$

Theorem: The average quantities of the orders entering the state are equal to the average quantities of the orders leaving the state in the unit time. Based on the theorem, we can obtain the following equations: 


$$
\begin{gathered}
\mu_{1} p_{1}=\mu_{0} p_{0} \\
\lambda_{0} p_{0}+\mu_{2} p_{2}=\left(\lambda_{1}+\mu_{1}\right) p_{1} \\
\lambda_{1} p_{1}+\mu_{3} p_{3}=\left(\lambda_{2}+\mu_{2}\right) p_{2} \\
\cdots \\
\lambda_{n-2} p_{n-2}+\mu_{n} p_{n}=\left(\lambda_{n-1}+\mu_{n-1}\right) p_{n-1} \\
\lambda_{n-1} p_{n-1}+\mu_{n+1} p_{n+1}=\left(\lambda_{n}+\mu_{n}\right) p_{n}
\end{gathered}
$$

So:

$$
\begin{array}{ll}
p_{1}= & \frac{\lambda_{0}}{\mu_{1}} p_{0} \\
p_{2}= & \frac{\lambda_{1} \lambda_{0}}{\mu_{2} \mu_{1}} p_{0} \quad \ldots \quad p_{n}=\frac{\lambda_{n-1} \lambda_{n-2} \ldots \lambda_{0}}{\mu_{n} \mu_{n-1} \ldots \mu_{1}} p_{0} \\
p_{3}=\frac{\lambda_{2} \lambda_{1} \lambda_{0}}{\mu_{3} \mu_{2} \mu_{1}} p_{0} &
\end{array}
$$

Additionally, the math distribution of the orders processing can be obtained in the steady state:

$$
p_{n}=\frac{\lambda_{n-1} \lambda_{n-2} \ldots \lambda_{0}}{\left(\mu_{n} \mu_{n-1} \ldots \mu_{1}\right) 1+\sum_{n=1}^{\infty} C_{n}}(n=1,2, \ldots)
$$

where: $\sum_{n=1}^{\infty} C_{n}$ is convergent.

\subsection{The resource exclusive mode}

The resource exclusive mode indicates that each supply chain can have a unique resource, and the unique resource solely provides service for itself; therefore, we can obtain:

(1) Service length

$$
L=\sum_{n=0}^{\infty} \mathrm{n} p_{n}=\sum_{n=1}^{\infty} \mathrm{n}(1-\rho) \rho^{n}=\frac{\rho}{1-\rho}=\frac{\lambda}{\mu-\lambda}
$$

where: $p_{n}=\rho^{n}(1-\rho)(n=1,2, \ldots) ; \rho=\frac{\lambda}{\mu} ; \lambda_{n}=\lambda, \mu_{n}=\mu$

(2) Service time

Supposing $n$ orders have existed when the new order arrives. According to the principle of "first come, first serve", the orders service time $T_{i}$ and the new order service time $T_{n+1}$ are composed of the new order staying time $W_{n}$, that is:

$$
W_{n}=T_{1}^{\prime}+T_{2}+\ldots+T_{n}+T_{n+1}
$$

where: $T_{1}^{\prime}$ is the remaining service time of the order, and $f(t \mid n+1)$ is the conditional probability density of $W_{n}$; so the probability density of $W_{n}$ is:

$$
f(t)=\sum_{n=0}^{\infty} p_{n} f(t \mid n+1)
$$

If $T_{i}(i=1, \ldots, n+1)$ is an Exponential distribution, $T_{1}^{\prime}$ is also an Exponential distribution (an Exponential distribution has no memory), then: 


$$
f_{v}(t)= \begin{cases}-\mu e^{-\mu t} & t>0 \\ 0 & t<0\end{cases}
$$

Therefore, $W_{n}$ is an Erlang distribution, that is: $\quad f(t \mid n+1)=\begin{gathered}\mu k(\mu k t)^{n+1-1} e^{-\mu k} \\ (n+1-1) !\end{gathered}$

$$
f(t \mid n+1)=\frac{\mu k(\mu k t)^{n+1-1} e^{-\mu k t}}{(n+1-1) !}=\frac{\mu(\mu t)^{n} e^{-\mu t}}{n !}
$$

where coefficient $k$ is 1 . Thenth $(\mu t)^{n} e^{-\mu t}$

$$
\begin{aligned}
f(t) & =\sum_{n=0}^{\infty}(1-\rho) \rho^{n} \frac{\mu(\mu t)^{n} e^{-\mu t}}{n !}=(1-\rho) \mu e^{-\mu t} \sum_{n=0}^{\infty} \frac{(\rho \mu t)^{n}}{n !} \\
& =(1-\rho) \mu e^{-\mu t} e^{\rho \mu t}=(\mu-\lambda) e^{-(\mu-\lambda) t}
\end{aligned}
$$

Therefore, $W_{n}$ is an Exponential distribution (parameter is $\mu$ - $\lambda$ ), and the service time of the order is:

$$
W=E(T)=\frac{1}{\mu-\lambda}=\frac{L}{\lambda}
$$

(3) Order loss

In orders processing, the on-time delivery (customer satisfaction) can be represented by the deviation between the order arrival time and the order required time. In a time window (see Fig. 2), the time segment $\left[0, T_{L i}\right]$ is the order arrival time that clients can accept, $T_{c i}$ is the order arrival time that clients expect, and $S_{T i}$ is the customer satisfaction.

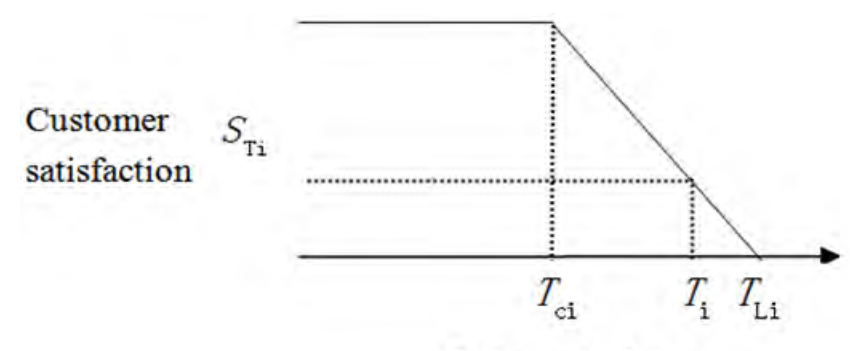

Order arrival time

Figure 2: The fuzzy description of customer satisfaction.

Therefore, the fuzzy membership function of customer satisfaction is:

$$
S_{\mathrm{Ti}}\left(T_{\mathrm{i}}\right)=\left\{\begin{array}{l}
1, T_{\mathrm{i}} \in\left[0, T_{\mathrm{ci}}\right] \\
\left(T_{\mathrm{Li}}-T_{\mathrm{i}}\right) /\left(T_{\mathrm{Li}}-T_{\mathrm{ci}}\right), T_{\mathrm{i}} \in\left[T_{\mathrm{ci}}, T_{\mathrm{Li}}\right] \\
0, T_{\mathrm{i}} \in\left[T_{\mathrm{Li}},+\infty\right]
\end{array}\right.
$$

where: $i$ is the order ID, and $T_{i}$ is the order arrival time. The function shows that the lower the order staying time is, the higher the customer satisfaction.

Assume there are two kinds of orders: one is timeliness orders (the first class of customers), and the other is ordinary orders (the second class of customers). Timeliness orders cannot receive preferential treatment in the resource exclusive mode; in addition, when the system resources are fully occupied, the loss rate for the first class of customers is $100 \%$, whereas the second class of customers can continue to wait. Therefore, the total customer loss rate is $P_{l}$ (there is at least one customer in the system).

(4) Utilization of resources

The utilization of resources refers to the degree of resources utilized. In general, a resource utilization of $70 \%-90 \%$ is more reasonable when the system is in the steady state. So resources utilization: 


$$
\rho_{\mathrm{i}}=\frac{\lambda_{i}}{\sum_{j=1}^{s} \mu_{j}}, i=1,2, \ldots s
$$

where $s$ is the service resources.

\subsection{The resource sharing mode}

The resource sharing mode indicates that $s$ supply chains have their unique resource; however, the unique resource can be shared with all orders. Therefore, we can obtain the following:

(1) Service length

When the system is in a steady state, the probability distribution of the service length is:

$$
p_{n}=p(N=n)(n=0,1,2 \ldots)
$$

Therefore,

$$
\lambda_{n}=\lambda(n=0,1,2 \ldots), \mu_{n}=\left\{\begin{array}{l}
n \mu(n=1,2 \ldots s) \\
s \mu(n=s, s+1, \ldots)
\end{array}\right.
$$

Additionally, $\rho_{s}=\frac{\rho}{s}=\frac{\lambda}{s \mu}, \rho_{s}<1$; therefore,

$$
p_{\mathrm{n}}=\left\{\begin{array}{l}
\frac{\rho^{n}}{n !} p_{0}(n=1,2 \ldots s) \\
\frac{\rho^{n}}{s ! s^{n-s}} p_{0}(n=s, s+1, \ldots)
\end{array}\right.
$$

where: $p_{0}=\left[\sum_{n=0}^{s-1} \frac{\rho^{n}}{n !}+\frac{\rho^{s}}{s !\left(1-\rho_{s}\right)}\right]^{-1}$.

Service length is shown below:

$$
\begin{aligned}
& L_{q}=\sum_{n=s+1}^{\infty}(n-s) p_{\mathrm{n}}=\frac{p_{0} \rho^{s}}{s !} \sum_{n=s}^{\infty}(n-s) \rho_{s}^{n-s} \\
& =\frac{p_{0} \rho_{s}}{s !} \frac{d}{d \rho_{s}}\left(\sum_{n=1}^{\infty} \rho_{s}{ }^{n}\right)=\frac{p_{0} \rho^{s} \rho_{s}}{s !\left(1-\rho_{s}\right)^{2}}=\frac{c(s, \rho) \rho_{s}}{1-\rho_{s}}
\end{aligned}
$$

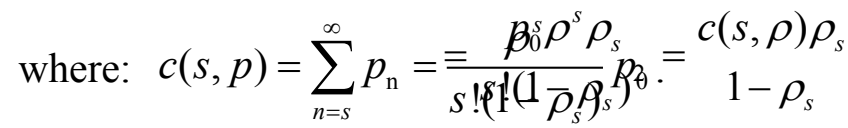

(2) Service time

Based on Eqs. (10) and (16), we obtain:

$$
W=\frac{c(s, \rho) \rho_{s}}{\left(1-\rho_{s}\right) \lambda}+\frac{1}{\mu}
$$

(3) Order loss

The orders arriving time is the Exponential distribution for the first/second class of customers (parameters are $\lambda_{1}$ and $\lambda_{2}$, respectively). There are at least $W$ service resources that are retained for the first class of customers; the service resources are independent of each other, and the service time is an Exponential distribution (parameter is $\mu$ ). When the service resources are fully occupied, the first class of customers will not enter the system; however, the second class of customers can wait. Therefore: 


$$
P_{\mathrm{j}}=\frac{\lambda_{0} \lambda_{1} \ldots \lambda_{j-1}}{\mu_{1} \mu_{2} \ldots \mu_{j}} P_{0}=\left\{\begin{array}{l}
\frac{\left(\lambda_{1}+\lambda_{2}\right)^{j}}{j ! \mu^{j}} P_{0}, 0 \leq j<s-W \\
\frac{\left(\lambda_{1}+\lambda_{2}\right)^{s-W} \lambda_{1}^{j-s+W}}{j ! \mu^{j}} P_{0}, j \geq s-W
\end{array}\right.
$$

where: $\quad P_{0}=\frac{1}{\sum_{j=0}^{s-W-1} \frac{\left(\lambda_{1}+\lambda_{2}\right)^{j}}{j ! \mu^{j}}+\sum_{j=s-W}^{s} \frac{\left(\lambda_{1}+\lambda_{2}\right)^{s-W} \lambda_{1}^{j-s+W}}{j ! \mu^{j}}}$

Therefore, the loss rate for the first class of customers is: $P_{s}=\frac{\left(\lambda_{1}+\lambda_{2}\right)^{s-W} \lambda_{1}^{W}}{s ! \mu^{W}} P_{0}$.

(4) Utilization of resources

In the resource sharing mode, the equation of the resources utilization differs from the resources exclusive mode, which is:

$$
\rho_{\mathrm{s}}=\frac{\lambda=\sum_{i=0}^{s} \lambda_{i}}{\sum_{j=1}^{s} \mu_{j}}
$$

An example in unit time, $\lambda=0.9, \mu=0.4, \lambda_{1}=\lambda_{2}=\lambda_{3}=0.9(s=3)$; therefore, the comparative results of the two modes are shown in Table I.

Table I: The comparison of indicators.

\begin{tabular}{|l|c|c|}
\hline \multicolumn{1}{|c|}{ Indicators } & Resource sharing mode & Resources exclusive mode \\
\hline Service length & 3.95 & 9 \\
\hline Service time & 4.39 & 10 \\
\hline Order loss & 0.039 & 0.186 \\
\hline Utilization of resources & 0.75 & 0.25 \\
\hline
\end{tabular}

Table I shows that the resource sharing mode has a great advantage over the resource exclusive mode in four aspects. Based on the theoretical model, this paper performs a simulation on the resource sharing's impact on the supply chain efficiency.

\section{SIMULATION PROCESS AND RESULTS}

\subsection{The concept model and simulation model}

Due to the theoretical analysis, the settings of the concept model are as follows: there are four chains; three are in the resource sharing mode, and one is in the resources exclusive mode. Therefore, the concept model is shown in Fig. 3, where the typical express supply chain includes the orders recipient, orders queuing, orders distribution (resources exclusive or resource sharing) and orders finished. In the resources exclusive mode, orders can solely be treated using private resources, whereas in the resource sharing mode, orders can be treated using common resources.

The simulation platform is an AnyLogic 6 University version, which is the simulation tool developed by XJ Technologies. The software is written in Java; the simulation program can be compiled in Java Applets and supports working on a Web page. In combination with the concept model and a simulation platform, the simulation concept is constructed (see Fig. 4). 


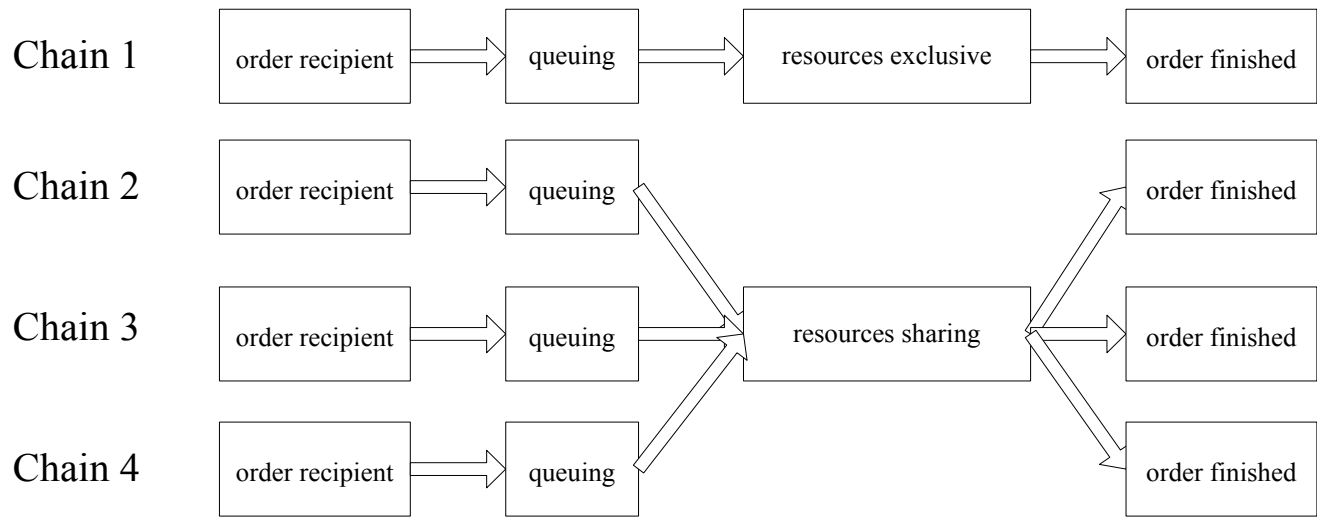

Figure 3: The concept model.

The settings are as follows in AnyLogic 6 University version:

(1) The order recipient time is an Exponential distribution (the parameter is 1.3); the order finished time is also an Exponential distribution (the parameter is 1.5);

(2) Unlimited service lengths and infinite service capabilities;

(3)There is solely one source (orders distribute) in the resources exclusive mode, and there are three sources (orders distribute) in the resource sharing mode;

(4) The simulation time is 200.

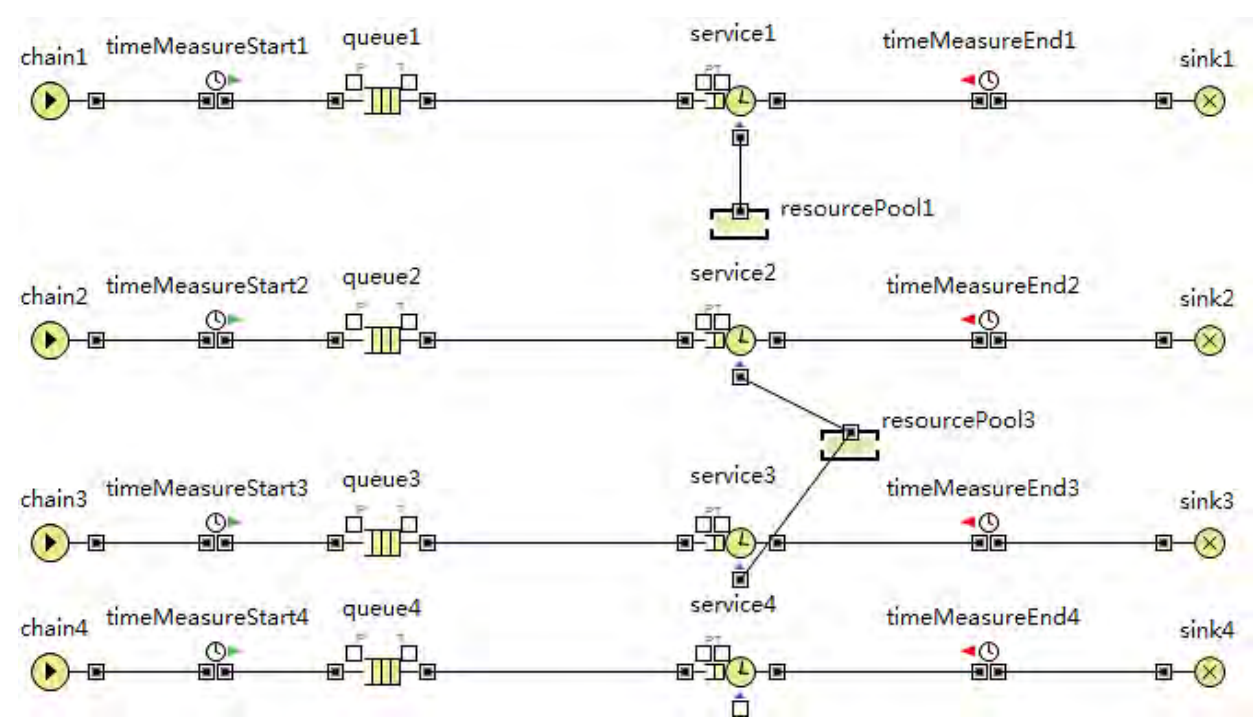

Figure4: The simulation model.

Based on the concept model and the simulation model, this paper analyses the resource sharing mode's impact on the service length, the service time, the order loss and the utilization of resources in the orders' treatment.

\subsection{The simulation results}

(1) Service length

In every experiment, we use the average value of 30 simulation results; the comparison of service length is shown in Table II.

Confidence test for simulation results. The standard Cronbach's alpha is 0.667 (95\% confidence). The results have a high confidence level when Cronbach's alpha is more than 0.6; therefore, the simulation is credible.

$T$-test for simulation results. Use '7.12' (in Experiment 1) for example. 
Table II: The comparison of service length.

\begin{tabular}{|c|c|c|c|c|c|}
\hline \multicolumn{2}{|c|}{ Mode } & $\begin{array}{c}\text { Resources } \\
\text { exclusive mode } \\
\text { (chain 1) }\end{array}$ & $\begin{array}{c}\text { Resource } \\
\text { sharing mode } \\
\text { (chain 2) }\end{array}$ & $\begin{array}{c}\text { Resource } \\
\text { sharing mode } \\
\text { (chain 3) }\end{array}$ & $\begin{array}{c}\text { Resource } \\
\text { sharing mode } \\
\text { (chain 4) }\end{array}$ \\
\hline \multirow{4}{*}{$\begin{array}{c}\text { Service } \\
\text { length }\end{array}$} & Experiment 1 & 7.12 & 2.44 & 2.21 & 2.58 \\
\cline { 2 - 6 } & Experiment 2 & 4.65 & 2.86 & 2.12 & 2.44 \\
\cline { 2 - 6 } & Experiment 3 & 9.41 & 1.67 & 1.64 & 1.67 \\
\cline { 2 - 6 } & Experiment 4 & 3.65 & 2.07 & 1.84 & 2.18 \\
\cline { 2 - 6 } & Experiment 5 & 5.2 & 2.17 & 2.32 & 2 \\
\cline { 2 - 6 } & Experiment 6 & 5.6 & 2.09 & 2.29 & 2.24 \\
\cline { 2 - 6 } & Experiment 7 & 5.28 & 2.58 & 2.35 & 2.8 \\
\cline { 2 - 6 } & Experiment 8 & 6.37 & 3.33 & 2.28 & 2.87 \\
\cline { 2 - 6 } & Experiment 9 & 4.9 & 2.26 & 2.17 & 1.95 \\
\cline { 2 - 6 } & Experiment 10 & 8.38 & 2.63 & 2.7 & 3.05 \\
\hline
\end{tabular}

Based on the law of Large Numbers, it is considered that 30 samples obey the Normal Distribution. The confidence interval of the $T$-test is ( $95 \%$ confidence):

$$
\left(\underline{x}-t_{(\alpha / 2, d f)} \frac{s}{\sqrt{n}}, \quad \underline{x}+t_{(\alpha / 2, d f)} \frac{s}{\sqrt{n}}\right)
$$

where: $\underline{x}$ is the sample mean, $t$ is the statistical value, $\alpha$ is the risk, $d f$ is the degree of freedom, $s$ is the sample standard deviation, and $n$ is the sample number.

The confidence interval is $[6.95,7.29]$; it explains that $95 \%$ of the simulation results are located in the interval $[6.95,7.29]$. The sample mean $(\underline{x}=7.12)$ serves as the simulation value (the same below).

Table II shows that the service length of the resources exclusive mode is much longer than the total service lengths of the resource sharing mode. For example, in Experiment 3, the service length is 9.41 in the resources exclusive mode, whereas the service length is 1.67 in the resource sharing mode; the three chains have no significant difference in the resource sharing mode.

(2) Service time

In every experiment, we use the average value of 30 simulation results; the comparison of the service time is shown in Table III.

Table III: The comparison of service time.

\begin{tabular}{|c|c|c|c|c|c|}
\hline \multicolumn{2}{|c|}{ Mode } & $\begin{array}{c}\text { Resources } \\
\text { exclusive mode } \\
\text { Indicator }\end{array}$ & $\begin{array}{c}\text { Resource } \\
\text { sharing mode } \\
\text { (chain 2) }\end{array}$ & $\begin{array}{c}\text { Resource } \\
\text { sharing mode } \\
\text { (chain 3) }\end{array}$ & $\begin{array}{c}\text { Resource } \\
\text { sharing mode } \\
\text { (chain 4) }\end{array}$ \\
\hline \multirow{4}{*}{ Service } \\
\cline { 2 - 6 } time & Experiment 1 & 6.1 & 1.96 & 1.96 & 1.96 \\
\cline { 2 - 6 } & Experiment 2 & 4.26 & 2.09 & 2.08 & 2.08 \\
\cline { 2 - 6 } & Experiment 3 & 5.35 & 1.38 & 1.38 & 1.38 \\
\cline { 2 - 6 } & Experiment 4 & 2.73 & 1.36 & 1.35 & 1.35 \\
\cline { 2 - 6 } & Experiment 5 & 4.8 & 1.71 & 1.71 & 1.71 \\
\cline { 2 - 6 } & Experiment 6 & 4.23 & 1.51 & 1.51 & 1.51 \\
\cline { 2 - 6 } & Experiment 7 & 4.18 & 2.21 & 2.21 & 2.22 \\
\cline { 2 - 6 } & Experiment 8 & 3.71 & 2.26 & 2.28 & 2.28 \\
\cline { 2 - 6 } & Experiment 9 & 4.4 & 1.65 & 1.65 & 1.65 \\
\cline { 2 - 6 } & Experiment 10 & 5.78 & 1.94 & 1.92 & 1.93 \\
\hline
\end{tabular}


The standard Cronbach's alpha is 0.834 (95\% confidence).

In Table III, the simulation results agree with the theoretical model; they show that the service time of the resources exclusive mode is equal or longer to the total service time of the resource sharing mode. For example, in Experiment 1, in the resources exclusive mode, the service time is 6.1 , whereas the total service time is 5.88 in the resource sharing mode; the three chains have no significant difference in the resource sharing mode.

(3) Loss rate

In every experiment, we use the average value of 30 simulation results. The first priority service is provided for Chain 2, the second priority is provided for Chain 3, and the last priority is provided for Chain 4. Customers will leave the system when the service time exceeds 1.1. The comparison of the loss rate is shown in Table IV.

Table IV: The comparison of loss rate.

\begin{tabular}{|c|c|c|c|c|c|}
\hline \multicolumn{2}{|c|}{ Mode } & $\begin{array}{c}\text { Resources } \\
\text { exclusive mode } \\
\text { Indicator }\end{array}$ & $\begin{array}{c}\text { Resource } \\
\text { sharing mode } \\
\text { (chain 2) }\end{array}$ & $\begin{array}{c}\text { Resource } \\
\text { sharing mode } \\
\text { (chain 3) }\end{array}$ & $\begin{array}{c}\text { Resource } \\
\text { sharing mode } \\
\text { (chain 4) }\end{array}$ \\
\hline \multirow{4}{*}{$\begin{array}{c}\text { Loss } \\
\text { rate }\end{array}$} & Experiment 1 & 1100 & 124 & 383 & 928 \\
\cline { 2 - 6 } & Experiment 2 & 1491 & 129 & 526 & 1267 \\
\cline { 2 - 6 } & Experiment 3 & 2032 & 165 & 631 & 1703 \\
\cline { 2 - 6 } & Experiment 4 & 1884 & 198 & 620 & 1630 \\
\cline { 2 - 6 } & Experiment 5 & 2336 & 242 & 829 & 2019 \\
\cline { 2 - 6 } & Experiment 6 & 1514 & 104 & 491 & 1234 \\
\cline { 2 - 6 } & Experiment 7 & 1638 & 159 & 561 & 1585 \\
\cline { 2 - 6 } & Experiment 8 & 793 & 75 & 318 & 729 \\
\cline { 2 - 6 } & Experiment 9 & 1733 & 187 & 550 & 1451 \\
\cline { 2 - 6 } & Experiment 10 & 1400 & 114 & 486 & 1252 \\
\hline
\end{tabular}

The standard Cronbach's alpha is 0.984 (95\% confidence).

Table IV shows that Chain 2 has the lowest loss rate of orders due to its special treatment of the first class of customers, and its loss rate is approximately $90 \%$ lower than that of the resources exclusive mode. Chain 3's loss rate is over $65 \%$ lower than that of the resources exclusive mode, although Chain 4's loss rate is nearly $20 \%$ lower than that of the resources exclusive mode. However, in the resources exclusive mode, the loss rate of orders will be $100 \%$ when the service time is over 1.1 .

This paper will continue to study the utilization of resources based on the research above.

(4) Utilization of resources

Similarly, in every experiment, we use the average value of 30 simulation results (the simulation time is 8000); the comparison of the resources utilization is shown in Table $\mathrm{V}$.

The standard Cronbach's alpha is 0.903 (95\% confidence).

In Table $\mathrm{V}$, for the service time/output, the output of the resource sharing mode is $20 \%$ higher than that of the resources exclusive mode in the same service time. For the resources utilization (the service time/simulation time is used), the utilization is approximately $80 \%$ in the resource sharing mode, whereas the utilization is $65 \%$ in the resources exclusive mode; in addition, the resources utilization should not be excessively large or excessively small. Therefore, not only can the resource sharing mode ensure the high utilization of resources, it can also address emergencies.

In sum, the resource sharing mode is superior to the resource exclusive mode regarding the service length, the service time, the loss rate and the utilization of resources' aspects; consequently, it can shorten the service time, increase the output and improve customer satisfaction. 
Table V: The comparison of resource utilization.

\begin{tabular}{|c|c|c|c|c|}
\hline \multirow{2}{*}{ Indicator } & \multicolumn{2}{|c|}{ Service time/output } & \multicolumn{2}{c|}{ Resources utilization } \\
\cline { 2 - 5 } Experiment & $\begin{array}{c}\text { Resources } \\
\text { exclusive mode }\end{array}$ & $\begin{array}{c}\text { Resource } \\
\text { sharing mode }\end{array}$ & $\begin{array}{c}\text { Resources } \\
\text { exclusive mode }\end{array}$ & $\begin{array}{c}\text { Resource } \\
\text { sharing mode }\end{array}$ \\
\hline Experiment 1 & $1434 / 1501$ & $1434 / 1773^{*}$ & 0.655 & $0.779^{*}$ \\
\hline Experiment 2 & $2096 / 2197$ & $2096 / 2576^{*}$ & 0.651 & $0.772^{*}$ \\
\hline Experiment 3 & $2357 / 2450$ & $2357 / 2982^{*}$ & 0.653 & $0.778^{*}$ \\
\hline Experiment 4 & $2880 / 3015$ & $2883 / 3570^{*}$ & 0.653 & $0.791^{*}$ \\
\hline Experiment 5 & $3513 / 3644$ & $3512 / 4347^{*}$ & 0.658 & $0.791^{*}$ \\
\hline Experiment 6 & $3355 / 3568$ & $3356 / 4183^{*}$ & 0.652 & $0.792^{*}$ \\
\hline Experiment 7 & $3845 / 3941$ & $3846 / 4597^{*}$ & 0.668 & $0.766^{*}$ \\
\hline Experiment 8 & $3393 / 3517$ & $3394 / 4113^{*}$ & 0.658 & $0.786^{*}$ \\
\hline Experiment 9 & $2626 / 2791$ & $2625 / 3291^{*}$ & 0.65 & $0.779^{*}$ \\
\hline Experiment 10 & $6637 / 6866$ & $6637 / 7874^{*}$ & 0.668 & $0.781^{*}$ \\
\hline
\end{tabular}

$*$ The average value of the three chains simulation results.

\section{CONCLUSION}

Supply chain resources usually refer to the organization's production factors, such as personnel, equipment, capital, technologies, knowledge, and information in supply chain services and working processes. Furthermore, with the development of the supply chain, the system will become increasingly complex, the bodies are very diverse, and supply chain activities cannot be achieved until the resource bodies are motivated and united. In particular, effectively coordinating and integrating the physical sources (personnel and equipment) is essential for effective supply chain management.

In this study, we focus on the express industry of Labors Limited and focus on the resource sharing mode's impact on the efficiency of the supply chain using the queuing theory and an AnyLogic simulation. The research shows that resource sharing can shorten the service length for low inventory, decrease the service time for an emergency, reduce the loss rate for high customer satisfaction and increase the resources utilization for low costs compared with the resources exclusive mode.

However, this paper has certain limitations and deficiencies. To guarantee the continuity of the theoretical model, much raw data are required for the simulation; however, the simulation studies are conducted based on the laboratory data instead of on raw data.

\section{ACKNOWLEDGEMENTS}

The study is supported by the National Natural Science Foundation (71132008, 71390334), and Beijing Municipal Science \& Technology Commission (Z121100000312093). We appreciate the support very much.

\section{REFERENCES}

[1] Lee, H. L. (2000). Creating value through supply chain integration, Supply Chain Management Review, from http://www.highbeam.com/doc/1G1-64972562.html, accessed on 05-06-2015

[2] Gong, D.; Liu, S. (2013). Holographic-based model for logistics resources integration, Studies in Informatics and Control, Vol. 22, No. 4, 367-376 
[3] Lepak, D. P.; Smith, K. G.; Taylor, M. S. (2007). Value creation and value capture: a multilevel perspective, Academy of Management Review, Vol. 32, No. 1, 180-194, doi:10.5465/ AMR.2007.23464011

[4] Rajsman, M.; Pros, N. (2014). Integrated management system of a transport company, Technical Gazette, Vol. 21, No. 5, 1165-1175

[5] Akanle, O. M.; Zhang, D. Z. (2008). Agent-based model for optimising supply-chain configurations, International Journal of Production Economics, Vol. 115, No. 2, 444-460, doi:10.1016/j.ijpe.2008.02.019

[6] Brintrup, A. (2010). Behaviour adaptation in the multi-agent, multi-objective and multi-role supply chain, Computers in Industry, Vol. 61, No. 7, 636-645, doi:10.1016/j.compind.2010.03. $\underline{010}$

[7] Jiao, J.; You, X.; Kumar, A. (2006). An agent-based framework for collaborative negotiation in the global manufacturing supply chain network, Robotics and Computer-Integrated Manufacturing, Vol. 22, No. 3, 239-255, doi:10.1016/j.rcim.2005.04.003

[8] Bronja, H.; Bronja, H. (2015). Two-phase selection procedure of aluminized sheet supplier by applying fuzzy AHP and fuzzy TOPSIS methodology, Technical Gazette, Vol. 22, No. 4, 821-828, doi:10.17559/TV-20140203122653

[9] Bhattacharyya, K. (2011). Value sourcing in supply chains, PhD Dissertation, Kent State University, Kent

[10] Prajogo, D.; Olhager, J. (2012). Supply chain integration and performance: The effects of long-term relationships, information technology and sharing, and logistics integration, International Journal of Production Economics, Vol. 135, No. 1, 514-522, doi:10.1016/ j.ijpe.2011.09.001

[11] Wamba, S. F.; Chatfield, A. T. (2009). A contingency model for creating value from RFID supply chain network projects in logistics and manufacturing environments, European Journal of Information Systems, Vol. 18, No. 6, 615-636, doi:10.1057/ejis.2009.44

[12] Salman, M. K.; Ahmad, R. B.; Yahya, A. (2014). A new approach for efficient utilization of resources in WIMAX cellar networks, Technical Gazette, Vol. 21, No. 6, 1385-1393

[13] Handfield, R. B.; Nichols Jr., E. L. (1999). Introduction to Supply Chain Management, Prentice Hall, Upper Saddle River

[14] Sahay, B. S. (2003). Supply chain collaboration: the key to value creation, Work Study, Vol. 52, No. 2, 76-83, doi: $10.1108 / 00438020310462872$

[15] Mavromoustakis, C. X.; Mastorakis, G.; Bourdena, A; Pallis, E. (2014). Energy efficient resource sharing using a traffic-oriented routing scheme for cognitive radio networks, IET Networks, Vol. 3, No. 1, 54-63, doi:10.1049/iet-net.2013.0132

[16] Yu, C.-H.; Doppler, K.; Ribeiro, C. B.; Tirkkonen, O. (2011). Resource sharing optimization for device-to-device communication underlaying cellular networks, IEEE Transactions on Wireless Communications, Vol. 10, No. 8, 2752-2763, doi:10.1109/TWC.2011.060811.102120

[17] Yang, G. (2015). A non-cooperative game approach for power control MAC in wireless sensor networks, Technical Gazette, Vol. 22, No. 2, 303-310, doi:10.17559/TV-20150312155401

[18] Chard, K.; Bubendorfer, K.; Caton, S.; Rana, O. F. (2012). Social cloud computing: A vision for socially motivated resource sharing, IEEE Transactions on Services Computing, Vol. 5, No. 4, 551-563, doi:10.1109/TSC.2011.39

[19] Gill, A. (2008). Identifying potential bottlenecks through activity under-utilization cost, International Journal of Simulation Modelling, Vol. 7, No. 4, 165-175, doi:10.2507/IJSIMM $\underline{07(4) 1.104}$

[20] Zaneldin, E. K. (2008). Resource optimization of construction operations using AOA-based simulation, International Journal of Simulation Modelling, Vol. 7, No. 3, 146-157, doi:10.2507/ IJSIMM07(3)4.109

[21] Marinković, Z.; Marinković, D.; Petrović, G.; Milić, P. (2012). Modelling and simulation of dynamic behaviour of electric motor driven mechanisms, Technical Gazette, Vol. 19, No. 4, 717-725 